\title{
Evaluation of Mini-Mental State Examination scores according to different age and education strata, and sex, in a large Brazilian healthy sample
}

\author{
Renata Kochhann $n^{1,2}$, Maria Otília Cerveira ${ }^{1,2}$, Cláudia Godinho3, \\ Analuiza Camozzato ${ }^{3}$, Márcia Lorena F. Chaves ${ }^{4}$
}

\begin{abstract}
Until better measures have been accepted for wider use, the Mini-Mental State Examination (MMSE) will continue to be utilized. In this context, knowledge on characteristics and determinants of its distribution for the Brazilian population are particularly valuable. The present study aimed to evaluate, based on multivariate analysis, the independent effect of age, educational level and sex, and their interactions, on MMSE scores in a healthy sample. Methods: Demographic data and scores on the MMSE of 1,553 healthy individuals were analyzed. The sample was grouped according to age and education. Results: The sample was composed of 963 females (62\%), mean age \pm SD was $49.6 \pm 20.7$ yrs (range 20 to $92 \mathrm{yrs).} \mathrm{The} \mathrm{mean} \mathrm{years} \mathrm{of} \mathrm{education} \pm$ SD was $8.9 \pm 5.5$ yrs (range 0 to $28 \mathrm{yrs}$ ). The mean score \pm SD on the MMSE was 27.3 \pm 2.7 (range 15 to 30). A significant effect of the interaction between education and $\operatorname{sex}(\mathrm{p}=0.011)$, and also between education and age was observed $(p=0.003)$. An independent effect of education $(p<0.001)$ and age $(p<0.001)$ was found. Participants from the higher educated group presented higher MMSE scores than the other groups. Younger adults presented higher MMSE scores than the other age groups. Conclusions: We observed an effect of education and age on MMSE scores. Younger individuals and higher educated participants presented higher scores.
\end{abstract}

Key words: Mini-Mental State Examination, cognition, cognitive assessment, educational attainment, age, sex.

Avaliação dos escores do Mini-Exame do Estado Mental de acordo com diferentes faixas de idade e escolaridade, e sexo, em uma grande amostra brasileira de sujeitos saudáveis

Resumo - O Mini-Exame do Estado Mental (MEEM) continuará sendo amplamente utilizado até que outras medidas sejam estabelecidas, por isso o conhecimento de características e determinantes de sua distribuição na população é particularmente útil. O presente estudo tem como objetivo avaliar o efeito independente e suas interações da idade, sexo e nível educacional em uma análise multivariada sobre os escores do MEEM em uma amostra saudável. Métodos: Dados demográficos e escores do MEEM de 1.553 indivíduos saudáveis foram analisados. A amostra foi agrupada de acordo com a idade e a educação. Resultados: A amostra foi composta de 963 mulheres (62\%), a média \pm DP da idade foi 49,6 $\pm 20,7$ (variando entre 20 e 92 anos). A média \pm DP dos anos de estudo foi 8,9 $\pm 5,5$ (variando entre 0 e 28 anos de estudo). A média \pm DP dos escores do MEEM foi 27,3 $\pm 2,7$ (variando entre 15 e 30). Um efeito significativo na interação entre educação e sexo foi observado $(p=0,011)$. Um efeito significativo na interação entre educação e idade também foi observado ( $p=0,003$ ). Um efeito independente da educação $(p<0,001)$ e da idade $(p<0,001)$ foi observado. Participantes do grupo com alto nível educacional apresentaram maiores escores no MEEM do que os participantes dos outros grupos. Do mesmo modo, adultos jovens apresentaram maiores escores no MEEM do que os participantes dos outros grupos etários. Conclusões: Nós observamos efeito da educação e da idade sobre os escores do MEEM. Indivíduos mais jovens e indivíduos com alto nível educacional apresentaram escores maiores no MEEM.

Palavras-chave: Mini-Exame do Estado Mental, cognição, avaliação cognitiva, nível educacional, idade, sexo.

\footnotetext{
1,2MD, Dementia Clinic, Neurology Service, Hospital de Clínicas de Porto Alegre. Medical Sciences Post-Graduate Course, UFRGS School of Medicine, Porto Alegre, RS, Brazil. ${ }^{3} \mathrm{MD}$, PhD, Dementia Clinic, Neurology Service, Hospital de Clínicas de Porto Alegre, Porto Alegre, RS, Brazil. ${ }^{4} \mathrm{MD}$, PhD, Internal Medicine Department, UFRGS School of Medicine, Porto Alegre, RS, Brazil.
}

Márcia L.F. Chaves - Rua Ramiro Barcelos, 2350 / sala 2040 - 90035-091 Porto Alegre RS - Brasil. E-mail: mchaves@hcpa.ufrgs.br

Disclosure: The authors report no conflicts of interest.

Received February 27, 2009. Accepted in final form May 12, 2009. 
The Mini-Mental State Examination (MMSE) was initially developed to screen dementia; however, it has been widely used as a measure of general cognitive functioning. The MMSE is the most widely used screening tool to assess mental or cognitive status in the elderly. Recently, the Brazilian Academy of Neurology ${ }^{1}$ and the American Academy of Neurology ${ }^{2}$ recommended the MMSE as a general cognitive screening instrument for the detection of dementia in individuals with suspected cognitive impairment. In Brazil, various cut-offs points have already been proposed for different educational levels with no consensus reached. However, efforts have been made to standardize its use. ${ }^{3}$ The high numbers of individuals with low levels of literacy yet high levels of illiteracy in some areas of the country, have made estimating the impact of schooling on MMSE scores very important, especially amid reports of reduced specificity ${ }^{4,5}$ among individuals with lower levels of education. ${ }^{6}$

Many studies have demonstrated the effect of age and education on MMSE scores ${ }^{7-12}$ (criterion validity), but education did not show any effect on construct validity. ${ }^{13} \mathrm{~A}$ longitudinal investigation carried out in healthy elders has shown lower MMSE performance in cognitively impaired elderly particularly among older elderly and the lower educated..$^{14} \mathrm{~A}$ large multicentric study in the USA showed the same influence of age and education on MMSE scores. ${ }^{15}$ In Brazil, the first evaluation of the impact of education was carried out in 530 subjects aged between 15 and 65 years. Significant differences among groups with different educational levels were observed but did not reach significance for age. ${ }^{16}$ The majority of other Brazilian studies have involved elderly individuals. ${ }^{17-21}$

Longitudinal and cross-sectional studies have shown an age effect on MMSE scores, with the latter having demonstrated stronger associations. ${ }^{22-24}$ Nevertheless, questions remains over whether age-related cognitive decline was normal ${ }^{24}$ or pathological. ${ }^{25}$

Gender differences in cognitive status have also been the subject of investigation with controversial results, in addition to uncertainty as to their correspondent mechanisms. Aspects related to lower female education, ${ }^{26}$ as well as biological differences such as atherosclerosis ${ }^{27-29}$ and hormonal profile ${ }^{30}$ may be involved. Studies have shown higher cognitive performance among women, independent of their lower education, ${ }^{31}$ while no such difference between men and women was observed among older participants. ${ }^{32}$ The applicability of the instruments of cognitive evaluation in different cultures and the impact of different variables such as education, age, and gender on results needs further assessment and standardizing.

In the present study we selected a large sample containing individuals of different ages, including younger par- ticipants, and education strata to evaluate the influence of these wide spectra on MMSE performance. The present study aimed to evaluate, based on multivariate analysis, the independent effect of age, educational level and sex, and their interactions, on MMSE scores in a healthy sample.

\section{Methods}

Healthy participants were randomly selected from different sectors of the Hospital de Clinicas de Porto Alegre (Porto Alegre, RS) (relatives, caregivers and visitors) to give a total sample of 1553 participants. Subjects were fully independent, non-demented, and aged from 20 to 92 years. Inclusion criteria were to be functionally independent and cognitively normal. Exclusion criteria were presence of any psychiatric or neurological disease and use of psychoactive drugs. To minimize inclusion of participants with incipient dementia among those aged $\geq 60$, subjects were screened with the Clinical Dementia Rating scale. ${ }^{33,34}$ All participants were tested for hearing ${ }^{35}$ and vision ${ }^{36}$ functions using brief screening tests (the whispered voice test for hearing and the self-reported measure for vision impairment).

Age was classified into different strata: younger adults (20 to 40 years), middle age (41 to 65 years), and older adults ( $\geq 66$ years). Distribution of education was analyzed in the whole sample to obtain the best categorization. The groups were classified as 0 to 5 years (low education), 6 to 11 years (medium education) and $\geq 12$ years of education (high education). Initially illiterates were placed in separate group, however, since analysis of MMSE performance in the 0 to 5 years of education group revealed no statistical difference ( $\mathrm{p}=0.09)$ (Bonferroni post-hoc test) these years of education were grouped together.

All participants were administered the Mini-Mental State Examination following the same protocol. ${ }^{37-38}$ The MMSE was the main outcome of the study (dependent variable). Age and education strata and sex were the independent factors.

The study was approved by the Ethics Committee for Medical Research at the Hospital de Clinicas de Porto Alegre. All subjects signed an informed consent before being enrolled onto the study.

\section{Data analysis}

Descriptive statistics (mean, SD, and relative frequency) were calculated for demographic data and the MMSE. A univariate general linear model (3-way ANOVA) was designed for the evaluation of the effects of age (young adults, middle age, older adults), education (low, medium, high), gender (male/female), and their interactions on MMSE scores, using the Bonferroni post-hoc test. Student's t test was used for comparing parametric data, and chi-square 
Table 1. Distribution of participants according to age and educational level.

\begin{tabular}{lc}
\hline Variable & Sample $(\mathbf{n}=\mathbf{1 5 5 3})$ \\
\hline Age $($ mean \pm SD) & $49.6 \pm 20.7$ \\
Age categories $(\mathrm{n}, \%)$ & \\
$\quad$ Younger adults & $559(36 \%)$ \\
$\quad$ Middle age & $565(36 \%)$ \\
$\quad$ Older adults & $429(28 \%)$ \\
Education (mean $\pm S D)$ & $8.9 \pm 5.5$ \\
Categories of education $(\mathrm{n}, \%)$ & \\
$\quad$ Low & $527(34 \%)$ \\
$\quad$ Medium & $430(28 \%)$ \\
$\quad$ High & $598(38 \%)$ \\
Gender & \\
$\quad$ Female $(\mathrm{n}, \%)$ & $963(62 \%)$ \\
MMSE $($ mean $\pm S D)$ & $27.3 \pm 2.7$ \\
\hline
\end{tabular}

test for categorical data. For categorization of education, the Bonferroni test was employed to compare MMSE scores by years of schooling. The statistical analysis was performed using the Statistical Package for the Social Sciences for Windows (SPSS 13).

\section{Results}

Age ranged from 20 to 92 years, education from 0 to 28 years and MMSE scores from 15 to 30 . The sample was grouped according to age and education. The demographic data of the sample is presented in Table 1.

A significant effect of the interaction between education and sex was observed $(\mathrm{p}=0.011)$ (Table 2). Women from the low education group presented lower MMSE scores than men in low and high education groups. A significant effect of the interaction between education and age was also observed ( $\mathrm{p}=0.003)$. Older participants from low education groups showed lower MMSE scores. An independent effect of education $(\mathrm{p}<0.001)$ and age $(\mathrm{p}<0.001)$ was observed. Participants from the high educated group presented higher MMSE scores than the other groups (Bonferroni post-hoc test). Younger adults presented higher MMSE scores than the other age groups (Bonferroni post-hoc test). Sex did not present an independent effect (not shown in Table 2). No interaction between age and sex was observed.

MMSE distribution according to age and education are displayed on Figures 1 and 2.

\section{Discussion}

This study was carried out to evaluate the effect of age, education and gender on MMSE scores in healthy participants. The interaction of education and sex presented a
Table 2. Mini-Mental State Examination (mean \pm SD) in General Linear Model analysis (3way-ANOVA): effect of age, education and sex (univariate model).

\begin{tabular}{lcc}
\hline Effect & $\begin{array}{c}\text { MMSE } \\
\text { Mean } \pm \text { SD }\end{array}$ & P value \\
\hline Age & & $<0.001$ \\
Younger adults (20-40 years) & $27.6 \pm 0.16$ & \\
Middle age (41-65 years) & $27.2 \pm 0.11$ & \\
Older adults ( $\geq 66$ years) & $26.7 \pm 0.13$ & \\
Education & & $<0.001$ \\
Low (0-5 years) & $26.2 \pm 0.15$ & \\
Medium (6-11 years) & $27.2 \pm 0.12$ & \\
High ( $\geq 12$ years) & $28.1 \pm 0.12$ & \\
Education* age & & 0.003 \\
Low & & \\
$\quad$ Younger adults & & \\
$\quad$ Middle age & $26.9 \pm 0.40$ & \\
$\quad$ Older adults & $26.0 \pm 0.16$ & \\
Medium & $25.7 \pm 0.17$ & \\
$\quad$ Younger adults & & \\
Middle age & $27.1 \pm 0.24$ & \\
Older adults & $27.7 \pm 0.19$ & \\
High & $27.0 \pm 0.23$ & \\
$\quad$ Younger adults & & \\
Middle age & $28.2 \pm 0.19$ & \\
Older adults & & \\
Education* sex & $27.9 \pm 0.16$ & \\
Low & & \\
$\quad$ Male & & \\
$\quad$ Female & $27.9 \pm 0.25$ & \\
Medium & & \\
$\quad$ Male & & \\
$\quad$ Female & & \\
High & & \\
$\quad$ Male & & \\
$\quad$ Female & & \\
\hline
\end{tabular}

significant effect on MMSE scores, as did the interaction between education and age. Age and education independently influenced MMSE scores, while sex alone did not affect this test.

The influence of education on cognitive performance has been demonstrated in other investigations. ${ }^{12,39-41}$ However, the findings of the present study - education, age, gender and the interactions effects - although not new, are important because they represent complementary knowledge to previous evaluations carried out in Brazil. We assessed all these effects and their interactions in a larger sample of healthy participants. It is also important to highlight the education effect, because it was not exactly linear. There was no significant difference in MMSE scores 
Dotted lines show means

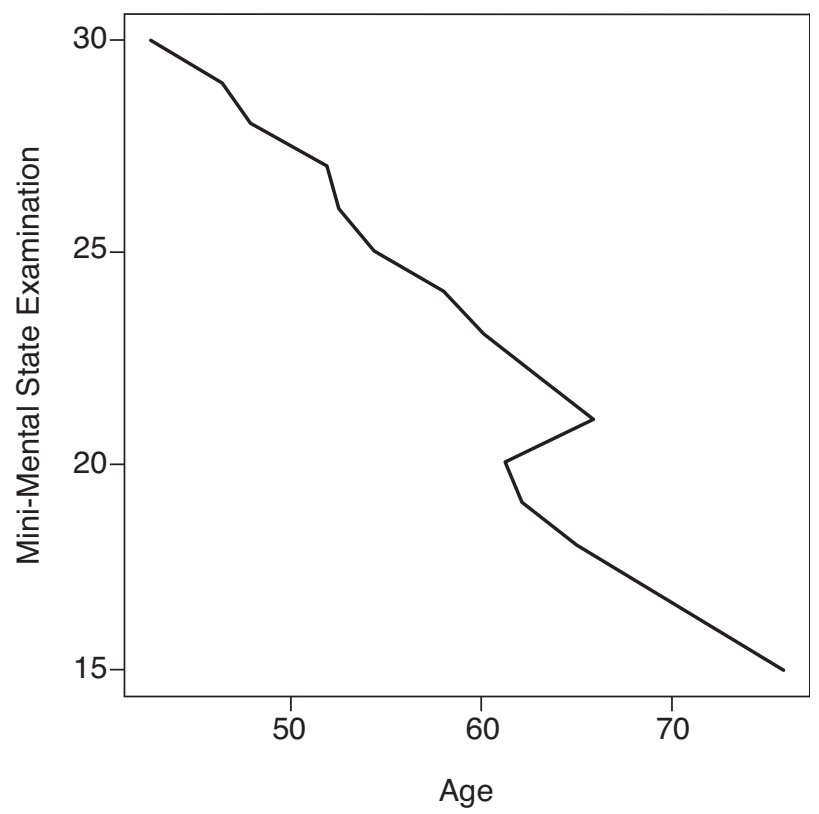

Figure 1. Distribution of Mini-Mental State Examination scores by age $(n=1553)$.

between illiterates and participants with 0 to 5 years of education. The difference was seen only in comparisons of participants with 6 years of schooling or more, suggesting that individuals without formal education (illiterates) as well as those with lower levels of education may present similar patterns on this mental status screening test. This finding differs to results of earlier studies carried out in other regions of Brazil. ${ }^{15,19}$

In Brazil, primary education is very heterogeneous, with regional characteristics, different yearly and daytime durations, and frequency of teachers. ${ }^{37}$ These differences tend to interfere in research evaluating cognitive performance. Sociological studies and educational evaluations have shown that educational systems reflect social inequalities causing different levels of learning attainment for the same number of years of schooling. ${ }^{42}$

The present study demonstrated a decline in MMSE performance among healthy individuals with age, reinforcing the notion that mental and cognitive status changes with aging may be unrelated to dementia or educational attainment. By taking into account cognitive status change as a normal aging finding, two other characteristics should be carefully considered for the diagnosis of dementia, functional status and intra-individual assessment.

Gender did not affect mental status. Results from studies on this association remain controversial. ${ }^{31,32}$ The cognitive difference observed between sexes has been partially attrib-
Dotted Lines show Means

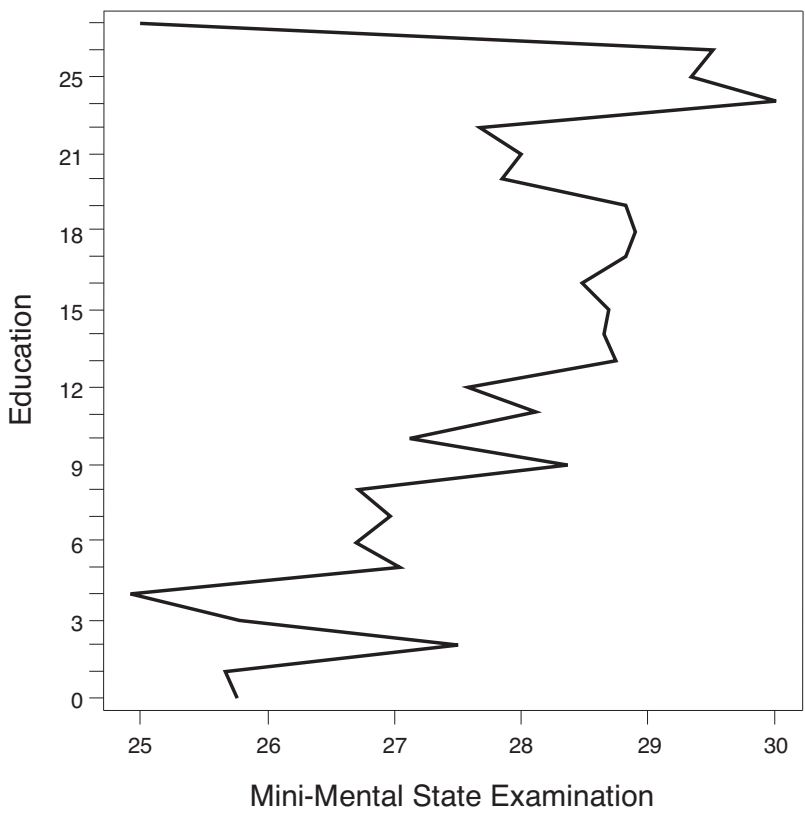

Figure 2. Distribution of Mini-Mental State Examination scores by education ( $n=1553)$.

uted to differential education of men and women (especially among older people), as well as to biological aspects. However, we observed no gender effect on MMSE scores.

Limitations of this study include the greater number of women in the sample, and the fact that participants were healthy - having been selected by excluding medical and psychiatric disorders - which restrict the results to individuals with a similar profile. On the other hand, the strength of the study is in its large sample of healthy participants which minimized the effect of other factors interfering with cognition. Finally, this study offered a rare opportunity to investigate MMSE scores in a large sample of individuals that presented a wide age and education range and who were deemed healthy with respect to conditions affecting cognitive performance.

\section{References}

1. Nitrini R, Caramelli P, Bottino CM, Damasceno BP, Brucki SM, Anghinah R. Diagnóstico de Doença de Alzheimer no Brasil. Avaliação cognitiva e funcional: Recomendações do Departamento Científico de Neurologia Cognitiva e do Envelhecimento da Academia Brasileira de Neurologia. Arq Neuropsiquiatr 2005;63:720-727.

2. Petersen RC, Stevens JC, Ganguli M, Tangalos EG, Cummings JL, Dekosky ST. Practice parameter: Early detection of dementia: Mild cognitive impairment (an evidence-based review) Report of the Quality Standards Subcommittee of the American Academy of Neurology. Neurology 2001;56:1133-1142. 
3. Castro-Costa E, Fuzikama C, Uchoa E, Firmo JO, Lima-Costa MF. Norms for the mini-mental state examination: adjustment of the cut-off point in population-based studies (evidences from the Bambuí health aging study). Arq Neuropsiquiatr 2008;66:524-528.

4. Gagnon M, Letenneur L, Dartigues JF, et al. The validity of the Mini-Mental State Examination as a screening instrument for cognitive impairment and dementia in French elderly community residents. Neuroepidemiology 1990;9:143-150.

5. Tombaugh TN, McIntyre NJ. The Mini-Mental State Examination: a comprehensive review. J Am Geriatr Soc 1992;40: 922-935.

6. Katzman R, Zhang M, Ya-Qu O, et al. A chinese version of the Mini-Mental State Examination; impact of illiteracy in a Shangai dementia survey. J Clin Epidemiol 1988;41:971-978.

7. Blesa R, Pujol M, Aguilar M, et al. Clinical validity of the 'Mini-Mental State' for Spanish speaking communities. Neuropsychologia 2001;39:1150-1157.

8. Fillenbaum G, Heyman A, Williams K, Prosnitz B, Burchett B. Sensitivity and specificity of standardized screens of cognitive impairment and dementia among elderly black and white community residents. J Clin Epidemiol 1990;43:651-660.

9. George LK, Landerman R, Blazer DG, Anthony JC. Cognitive impairment. In: Robbins LN, Regier DA (Eds). Psychiatric disorders in America: The epidemiologic catchment area study. New York: Free Press, 1991; 237-291.

10. Launer LJ, Dinkgreve MA, Jonker C, Hooijer C, Lindeboom $\mathrm{J}$. Are age and education independent correlates of the MiniMental State Exam performance of community-dwelling elderly? J Gerontol 1993;48:271-277.

11. Murden RA, McRae TD, Kaner S, Bucknam ME. Mini Mental Status Exam scores with education in Blacks and Whites. J Am Geriatr Soc 1991;43:138-145.

12. Rosselli D, Ardila A, Pradilla G, et al. El Examen Mental abreviado (Mini Mental State Examination) como prueba de selección para el diagnostico de demencia: Estudio poblacional colombiano. Rev Neurol 2000;30:428-432.

13. Castro-Costa E, Fuzikawa C, Ferri CP, et al. Dimensions underlying the Mini-mental State Examination in a sample with low education levels The Bambui Health and Aging Study (BHAS). Am J Geriatr Psychiatry, 2009 (in press).

14. Jacqmin-Gadda H, Fabrigoule C, Commenges D, Dartigues JF. A 5-year longitudinal study of the Mini-Mental State Examination in normal aging. Am J Epidemiol 1997;145:498-506.

15. Crum RM, Anthony JC, Basset SS, Folstein MF. Populationbased norms for the Mini-Mental State Examination by age and education level. J Am Med Assoc 1993;269:2386-2391.

16. Bertolucci PH, Brucki SM, Campacci SR, Juliano Y. O miniexame do estado mental em uma população geral: impacto da escolaridade. Arq Neuropsiquiatr 1994;52:1-7.

17. De Brito-Marques PR, Cabral-Filho JE. The role of educa- tion in Mini-Mental State Examination: A study in Northeast Brazil. Arq Neuropsiquiatr 2004;62:206-211.

18. Lourenço RA, Veras RP. Mini-Mental State Examination: psychometric characteristics in elderly outpatients. Rev Saude Publica 2006;40:712-719.

19. Almeida OP. The Mini-Mental State Examination and the Diagnosis of Dementia in Brazil. Arq Neuropsiquiatr 1998;56:605-612.

20. Laks J, Baptista EM, Contino AL, Paula EO, Engelhardt E. Mini-Mental State Examination norms in a communitydwelling sample of elderly with low schooling in Brazil. Cad Saude Publica 2007;23:315-319.

21. Scazufca M, Almeida O, Vallada HP, Tasse WA, Menezes PR. Limitations of the Mini-Mental State Examination for screening dementia in a community with low socioeconomic status. Eur Arch Psychiatry Clin Neurosci 2009;259:8-15.

22. Jacqmin-Gadda H, Fabrigoule C, Commenges D, Letenneur L, Dartigues JF. A cognitive screening battery for dementia in the elderly. J Clin Epidemiol 2000;53:980-987.

23. Izak GJ, Gussekloo J, Dermout KMT, Heeren TJ, Ligthart GJ. Three-year follow-up of Mini-Mental State Examination score in community residents aged 85 and over. Psychol Med 1995;25:841-848.

24. Brayne C, Gill C, Paykel ES, Huppert F, O'Connor DW. Cognitive decline in an elderly population - A two-wave study of change. Psychol Med 1995;25:673-683.

25. Starr JM, Deary IJ, Inch S, Cross S, MacLennan WJ. Age-associated cognitive decline in healthy old people. Age Ageing 1997;26:295-300.

26. Schmand B, Smit JH, Geerlings MI, et al. The effects of intelligence and education on the development of dementia. A test of the brain reserve hypothesis. Psychol Med 1997;27:1337-1344.

27. Breteler MM, Claus JJ, Grobbee DE, et al. Cardiovascular disease and distribution of cognitive function in elderly people: the Rotterdam study. BMJ 1994;308:1604-1608.

28. Hofman A, Ott A, Bretler MM, et al. Atherosclerosis, apolipoprotein E, and prevalence of dementia and Alzheimer's disease in the Rotterdam study. Lancet 1997;349:151-154.

29. Orencia A, Bailey K, Yawn BP, et al. Effect of gender on longterm outcome of angina pectoris and myocardial infarction/ sudden unexpected death. JAMA 1993;269: 2392-2397.

30. Resnick SM, Metter EJ, Zonderman AB. Estrogen replacement therapy and longitudinal decline in visual memory. A possible protective effect? Neurology 1997;49:1491-1497.

31. Van Exel E, Gussekloo J, de Craen AJM, et al. Cognitive function in the oldest old: women perform better than men. J Neurol Neurosurg Psychiatry 2001;71:29-32.

32. Black SA, Espino DV, Mahurin R, et al. The Influence of Noncognitive Factors on the Mini-Mental State Examination in Older Mexican-Americans: Findings from the Hispanic EPESE. J Clin Epidemiol 1999;52:1095-1102. 
33. Hughes CP, Berg L, Danziger WL, et al. A new clinical scale for the staging of dementia. Br J Psychiatry 1982;140:566-572.

34. Chaves ML, Camozzato A, Godinho C, et al. Validity of the Clinical Dementia Rating Scale for The Detection and Staging of Dementia in Brazilian Patients. Alzheimer Dis Assoc Disord 2007; 21:210-217.

35. Pirozzo S, Papinczak T, Glasziou P. Whispered voice test for screening for hearing impairment in adults and children: systematic review. BMJ 2003;327(7421):967-971.

36. Smeeth L, Iliffe S. Community Screening for Visual Impairment in Older People. J Am Geriatr Soc 2001;49:673-675.

37. Chaves ML, Izquierdo IA. Differential Diagnosis between Dementia and Depression: a Study of Efficiency Increment. Acta Neurol Scand 1992;85:378-382.

38. Brucki SM, Nitrini R, Caramelli P, Bertolucci PH, Okamoto IH. Sugestões para o uso do Mini-Exame do Estado Mental no Brasil. Arq Neuropsiquiatr 2003;61:777-781.
39. Grigoletto F, Zappalà G, Anderson DW, Lebowitz BD. Norms for the Mini-Mental State Examination in a healthy population. Neurology 1999;53:315-320.

40. Espino DV, Lichtenstein MD, Palmer RF, Hazuda HP. Ethnic differences in Mini-Mental State Examination (MMSE) scores: Where you live makes a difference. J Am Geriatr Soc 2001;49:538-548.

41. Kahle-Wrobleski K, Corrada MM, Li B, Kawas CH. Sensitivity and Specificity of the Mini-Mental State Examination for Identifying Dementia in the Oldest-Old: The 90+ Study. J Am Geriatr Soc 2007;55:284-289.

42. Ribeiro VM, Soares TM. Construção de escala combinada de proficiência em leitura e matemática para a medição do alfabetismo entre jovens e adultos em contextos não escolares. Disponível em: http://www.acaoeducativa.org.br/portal/ images/stories/pdfs/artigo2008construcaodeescalacombinada.pdf. Acessado em: 08/01/09. 